\title{
Meconium Stained Amniotic Fluid and Antenatal Steroid Administration at Term
}

\author{
Dawood AS* and Dawood AS \\ Department of Obstetrics and Gynecology, Tanta \\ University, Tanta, Egypt \\ *Corresponding author: Ayman Shehata Dawood, \\ Department of Obstetrics and Gynecology, Tanta \\ University, Tanta, Egypt
}

Received: November 15, 2017; Accepted: December 08, 2017; Published: December 15, 2017

\begin{abstract}
Nowadays evidence has suggested great benefits to antenatal steroids given to pregnant women after $\geq 37$ weeks if elective cesarean delivery is planned. This evidence resulted into abuse of steroids in all term pregnancies without differentiation between high risk and low risk patients. In this study we demonstrated some undesired side effects due to antenatal steroids for both fetus and mother.
\end{abstract}

Keywords: Antenatal steroids; Term pregnancy; Elective cesarean delivery; Steroids side effects

\section{Introduction}

Antenatal steroids were encouraged to be given in term pregnancies when elective cesarean section is planned. Evidence suggested that steroids at term improve neonatal outcomes by reduction in respiratory morbidities and neonatal ICU admissions $[1,2]$.

This results in wide use or abuse of antenatal steroids in all patients before planned term cesarean deliveries regardless of gestational age, maternal medical diseases or fetal maturity. Steroids are not without complications and many reported undesired effects were linked to administration of steroids during pregnancies. The commonly reported side effects were increased rates of infections including endometritis and chorionamnionitis especially in women with Premature Rupture of Membranes (PROM). Steroids were also linked to wound complications either infection or poor wound healing due to increase blood glucose levels. On the fetal side, steroids were linked to reduced fetal movements and fetal heart rate variation. Also multiple courses of steroids affect fetal growth, neonatal birth weight and early-onset neonatal sepsis [3].

In this study, we reported meconium stained amniotic fluid with respiratory complications related to routine use of steroids before elective term cesarean deliveries.

\section{Patients and Methods}

\section{Study design and settings}

This study is an observational study, conducted in Department of Obstetrics and Gynecology, Tanta University, in the period from September, 1, 2016 to August, 31, 2017.

\section{Patients}

The enrolled patients $(n=70)$ were admitted to antenatal unit for elective cesarean delivery. Patients included were primigravidae, full term $\geq 37$ weeks, carrying single bay, and with average BMI (19-25). The exclusion criteria were preterm deliveries, cases with PROM, multiple gestation, cases with abnormally located or adherent placenta, anemic and diabetic patients.

\section{Methods}

All patients were given Dexamethasone 6mg IM every 12 hours for 4 doses with the last dose 24 hours before planned elective cesarean delivery. All cases were operated by the same surgeon, and receiving all spinal anesthesia.

\section{Data collection}

Patients' demographic data, causes of cesarean delivery, operative data and complications, post-operative complications, and wound complications assessed 7 days after cesarean delivery. The newborn was assessed for meconium aspiration, respiratory distress, transient tachypnea of newborn, the need for incubation or neonatal ICU and blood glucose levels.

\section{Ethical approval}

This study was approved by local ethical committee of Tanta University before start of the study.

\section{Statistical methods}

Data were analyzed by SPSS version 18 (USA, Chicago). The number, percentage, range, mean, and standard deviation were used in this study.

\section{Results}

The demographic data of enrolled patients including maternal age, gestational age at delivery and BMI were demonstrated in Table

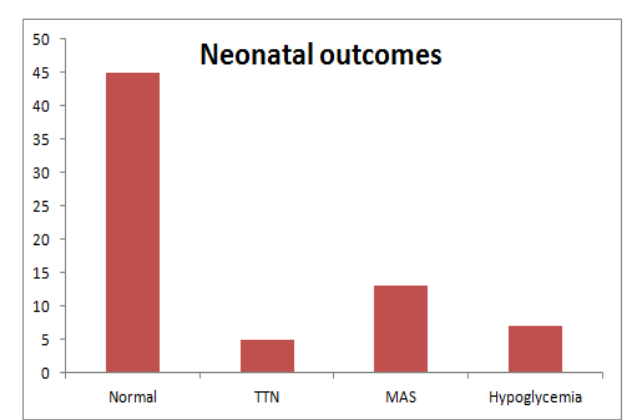

Figure 1: Neonatal outcomes in the studied cases. TTN: Transient Tachypnea Of Newborn; MAS: Meconium Aspiration Syndrome. 


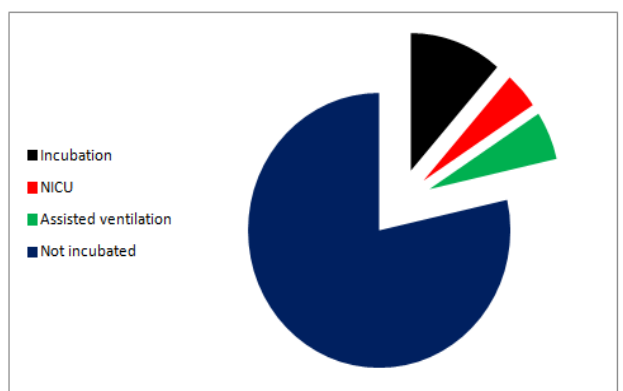

Figure 2: The neonates requiring advanced care. NICU: Neonatal Intensive Care Unit.

Table 1: Demographic data of enrolled patients.

\begin{tabular}{|c|c|c|}
\hline & Range & Mean \pm SD \\
\hline Age (years) & $22-37$ & $28.16 \pm 4.4$ \\
\hline BMI & $19-25$ & $22.82 \pm 3.9$ \\
\hline Gestational age (weeks) & $37-41$ & $38.39 \pm 1.2$ \\
\hline \multicolumn{3}{|c|}{ Causes of cesarean delivery } \\
\hline Malpresentations & \multicolumn{2}{|c|}{$36(51.43 \%)$} \\
\hline Fetal macrosomia & \multicolumn{2}{|c|}{$3(4.29 \%)$} \\
\hline Cesarean on request & \multicolumn{2}{|c|}{$25(35.71 \%)$} \\
\hline Old primigravida & \multicolumn{2}{|c|}{$6(8.57 \%)$} \\
\hline
\end{tabular}

1. Causes of elective cesarean section were listed in Table 1.

The operative data were presented in table 2 , where the mean operative time was $34.31 \pm 5.27$ minutes; the mean blood loss was $584.72 \pm 88.91 \mathrm{ml}$. There were 13 cases $(18.57 \%)$ with meconium stained amniotic fluid. The postoperative complications were fever in 15 cases $(21.43 \%)$, and wound sepsis in 23 cases (32.86\%).

The recorded neonatal complications were transient tachypnea of newborn (TTN) in 5 cases (7.14\%), Meconium Aspiration Syndrome (MAS) in 13 cases, and neonatal hypoglycemia in 7 cases (10.00\%). The babies who required advanced neonatal care were 8 cases $(11.43 \%)$ that required ordinary incubation with nasal oxygen only, 4 cases $(5.71 \%)$ that required assisted ventilation and 3 cases $(4.29 \%)$ that required Neonatal Intensive Care Unit (NICU). These findings are shown in Figure 1, 2.

\section{Discussion}

Corticosteroid are similar to all drugs has benefits and side effects. Administration of steroids during pregnancy was limited to a specified period of gestation between 24-34 weeks and given only for risky patients for preterm labour. Evidence also advocated single course rather than repeated courses [4].

Nowadays, many studies advocated the use of antenatal steroids beyond 34 weeks to full term being of great value in reducing respiratory composite morbidities. Moreover, steroids are being described before elective full term cesarean delivery if planned before 39 weeks. The studies in this issue reached to a conclusion of its value in reducing TTN, and incubation admissions $[5,6]$.

Most studies focused lights on the short-term outcomes without adequate studies on the delayed effects of steroids. This lead
Table 2: Operative and post-operative findings in enrolled patients.

\begin{tabular}{|c|c|c|}
\hline & Range & Mean \pm SD \\
\hline Operative time (minutes) & $25-40$ & $34.31 \pm 5.27$ \\
\hline \multicolumn{3}{|c|}{ Meconium stained amniotic fluid } \\
\hline Yes & \multicolumn{2}{|c|}{$13(18.57 \%)$} \\
\hline No & \multicolumn{2}{|c|}{$57(81.43 \%)$} \\
\hline Blood loss (ml) & $500-700$ & $584.72 \pm 88.9$ \\
\hline \multicolumn{3}{|c|}{ Postoperative complications } \\
\hline \multicolumn{3}{|c|}{ Fever } \\
\hline Yes & \multicolumn{2}{|c|}{$15(21.43 \%)$} \\
\hline No & \multicolumn{2}{|c|}{$55(78.57 \%)$} \\
\hline \multicolumn{3}{|c|}{ Wound sepsis } \\
\hline Yes & \multicolumn{2}{|c|}{$23(32.86 \%)$} \\
\hline No & \multicolumn{2}{|c|}{$47(67.14 \%)$} \\
\hline
\end{tabular}

arise of some voices requiring re-visiting the evidence of steroid administration at term as many drugs were at first advised then when its safety was established; these drugs were panned [7].

In the current study, antenatal steroids were linked to some cases of meconium stained amniotic fluid in 13 cases (18.57\%) and wound sepsis in 23 cases $(32.86 \%)$. The neonatal respiratory morbidities were present in 15 cases (21.43\%). Similar results were reported by Mariotti et al, (2004) who found that steroids were linked to both maternal and fetal complications [3].

Waffarn et al, (2012) in their review study concluded that exposure to single and repeated courses of steroids in-utero leads to neonatal hypothalamo-pituitary-adrenal (HPA) axis dysregulation. The longterm clinical outcomes in humans such as subtle neurodevelopmental outcomes and difficult stress tolerance, learning difficulties, and poor cognitive behavior are still not well studies [8]. On the same side, Asztalos et al, ( 2012) stated that the potential impact of antenatal steroids on future generation in relation to behavior, learning skills, and chronic illness are still unknown and appropriate measures to minimize these effects should be implemented [9].

A surprising results were reported by McLaughlin et al, (2003) who found that not benefit from corticosteroid treatment during pregnancy and that the infants who were exposed to steroids in-utero had 3 times higher mortality than non-exposed infants [10].

On institutional level, the Society for Maternal-Fetal Medicine (SMFM) advocated the use of a single course of antenatal steroids in late preterm in risky patients for preterm labour only. The society depended on the lack of long-term safety data in their decision. The American College of Obstetricians and Gynecologists expanded their guidelines to include gestations from 23 to 37 weeks. Neither organization has advocated for steroids use at term prior to cesarean delivery $[11,12]$.

Moreover a study done by Kamath-Rayne et al, (2012) conducted a study to compare the outcomes of neonates born $\geq 34$ weeks with evident lung maturity testing with immature fetuses treated with antenatal corticosteroids followed by planned delivery within 1 week. They found that antenatal corticosteroids in immature babies did not reduce respiratory morbidity in neonates born $\geq 34$ weeks of gestation 
[13].

\section{Conclusion}

Antenatal steroids are not fully safe and are linked to both fetal and maternal side effects. In this study we reported some cases of meconium stained amniotic fluid related to steroids use at term. Antenatal steroids administration at term should be re-evaluated and not be given to all patients as a routine daily practice before term elective cesarean section.

\section{References}

1. Saccone G, Berghella V. Antenatal corticosteroids for maturity of term or near term fetuses: systematic review and meta-analysis of randomized controlled trials. BMJ. 2016; 355: IS044.

2. Stutchfield PR, Whitaker R, Gliddon AE, Hobson L, Kotecha S, Doul IJM. Behavioural, educational and respiratory outcomes of antenatal betamethasone for term caesarean sect (ASTECS trial). Arch Dis Child Fetal Neonal Ed. 2013; 98: F195-F200.

3. Mariotti V, Marconi AM, Pardi G. Undesired effects of steroids during pregnancy. J Matern Fetal Neonatal Med. 2004; 16: 5-7.

4. Shields A, Thomson M, Winter V, Coalson J, Rees S. Repeated courses of antenatal corticosteroids have adverse effects on aspects of brain development in naturally delivered baboon infants. Pediatric research. 2012 71: 661-667.

5. Gyamfi-Bannerman C, Thom EA, Blackwell SC, Tita ATN, Reddy UM, Saade $\mathrm{GR}$, et al. Antenatal betamethasone for women at risk for late preterm delivery. NEJM 2016 SMFM Publications Committee, SMFM statement: implementation of the use of antenatal corticosteroids in the late preterm birth period in women at risk for preterm delivery. Am J Obstet Gynec. 2016.

6. Kemp MW, Newnham JP, Challis JG, Jobe AH, Stock SJ. The clinical use of corticosteroids in pregnancy. Human Reproduction Update. 2015; 22: 240 259.

7. Guinn DA. Should we take another look at antenatal corticosteroids? 2017

8. Waffarn F, Davis EP. Effects of Antenatal Corticosteroids on the HypothalamicPituitary-Adrenocortical Axis of the Fetus and Newborn: Experimental Findings and Clinical Considerations. American journal of obstetrics and gynecology. 2012; 207: 446-454.

9. Asztalos E. Antenatal corticosteroids: a risk factor for the development of chronic disease. Journal of nutrition and metabolism. 2012.

10. McLaughlin KJ, Crowther CA, Walker N, Harding JE. Effects of a single course of corticosteroids given more than 7 days before birth: a systematic review. Australian and New Zealand journal of obstetrics and gynaecology. 2003; 43: 101-106.

11. SMFM Publications Committee, SMFM statement: implementation of the use of antenatal corticosteroids in the late preterm birth period in women at risk for preterm delivery. Am J Obstet Gynecol. 2016.

12. Committee on Fetus and Newborn. Adarrkin DH. Postnatal glucose homeostasis in late-preterm and term infants. Pediatrics. 2011; $127:$ 575-579.

13. Kamath-Rayne BD, DeFranco EA, Marcotte MP. Antenatal Steroids for Treatment of Fetal Lung Immaturity after 34 Weeks of Gestation: An Evaluation of Neonatal Outcomes. Obstetrics and gynecology. 2012; 119: 909-916.
Austin J Obstet Gynecol - Volume 4 Issue 4 - 2017

Submit your Manuscript | www.austinpublishinggroup.com

Dawood et al. (C) All rights are reserved
Citation: Dawood AS and Dawood AS. Meconium Stained Amniotic Fluid and Antenatal Steroid Administration at Term. Austin J Obstet Gynecol. 2017; 4(4): 1086. 